\title{
Method for measuring the resistances produced on parallel and perpendicular veneers in plywood under nail embedment loading
}

\author{
Keita Ogawa* (D, Masaki Harada, Tatsuya Shibusawa and Kohta Miyamoto
}

\begin{abstract}
The resistance of wooden materials against embedment loading is an important property that governs the performance of timber joints with dowel-type fasteners including nails. When plywood is used as a sheet material in a nailed joint, veneers with different grain directions are simultaneously embedded. The resistance produced on individual veneers has to be measured to elucidate the embedment properties of plywood. This study proposes a method for measuring resistance on individual veneers. Embedment behavior was modeled using springs arranged in parallel, and the equations for calculating resistance on individual veneers were derived. Embedment tests were conducted using structural plywood composed of sugi or karamatsu. Mechanical behaviors of individual veneers were revealed as followings. In the initial range of deformation, the slope of the resistance-deformation relationship of the veneer with grain parallel to the load direction is higher than that of the resistance-deformation relationship of the veneer with grain perpendicular to the load direction. The parallel veneer began to yield under a low range of deformation, and the resistance of the perpendicular veneer under a high range of deformation became almost equal to that of the parallel veneer.
\end{abstract}

Keywords: Plywood, Embedment, Nail, Load-deformation relationship, Spring model

\section{Introduction}

Plywood-sheathed structural diaphragms with nailed joints are commonly used in the construction of light wooden frames or other types of structures. Past studies have shown that the in-plane shear resistance performance of the diaphragms is mainly dominated by the shear performance of the nailed joints [1-4]. The embedment behavior of wood by a nail is an important characteristic that strongly influences the shear performance of the joints. This characteristic has been used to analyze or predict shear performances on the basis of European Yield Theory [5, 6], elastic foundation model [7-12], and finite element method [13-15]. Therefore, the embedment behavior of wood and wood-based materials by a nail must be clarified. The embedment behaviors of various types of wooden materials by dowel-type fasteners

*Correspondence: ogawakeita@ffpri.affrc.go.jp

Forestry and Forest Products Research Institute, Matsunosato, Tsukuba, Ibaraki 305-8687, Japan have been investigated under different loading conditions. For example, Chui and $\mathrm{Ni}$ [16] conducted embedment tests on spruce, maple, and plywood specimens under reversed cyclic load. Jeon and Kong [17] evaluated the embedment behavior of glulam specimens made of Japanese cedar by ash pegs. Bal [18] investigated the characteristics of plywood reinforced with glass fiber fabric. Sawata and Sasaki [19] evaluated the embedment properties of decay-treated solid wood specimen.

When the load is applied to the structural diaphragms with nailed joints, the joints are loaded from many angles. Then, the influence of the grain direction of wood or wood-based material on the embedment behavior is of major concern. Jeong et al. [20] subjected glulam specimens made of Japanese cedar to embedment tests. They applied load on longitudinal, radial, and tangential directions and obtained the highest load capacity in the longitudinal direction. Bleron et al. [21] investigated the embedment characteristics of a gonfolo rose specimen with various grain directions. Under embedment 
load applied perpendicular to the grain direction, lower load at plastic threshold and higher maximum load were observed than the case of parallel.

Plywood is a wood-based panel material produced by alternately laminating veneers with parallel and perpendicular grain directions. The grain direction of each veneer may affect embedment behavior in plywoodsolid wood nail joints. On the shear performance of plywood-solid wood nailed joints, the effect of the grain direction of plywood has been investigated under single-shear loading. Stewart [22] conducted a single-shear test with nailed joint specimens. He prepared two types of plywood joint specimens. In the joint specimes, the plywood was attached to become that the grain direction of surface veneer were parallel or perpendicular to the load direction. The load-deformation curves of the two types of specimens were not considerably different. Harada et al. [23] conducted the tests with similar types of specimen and reported no large difference in maximum load. However, the deformation at maximum load in the case of plywood with perpendicular grain of the surface veneer was higher than that of parallel grain. Meanwhile, Demirkir and Colakoglu [24] reported that stiffness was higher when the surface direction of plywood was parallel to the loading direction than when the surface direction of plywood was perpendicular to the loading direction. Hagiwara [25] reported no difference in shear performance between the parallel and perpendicular grain directions of plywood. However, when the angle between the grain and load directions was $30^{\circ}, 45^{\circ}$ or $60^{\circ}$, resistance performance decreased under a small load range.

The resistance of nailed joints under single-shear loading is determined by various factors, e.g., bending properties of nail, pull out strength of nail from wood, nail-head pull-through resistance. In addition, the combination of plywood embedment and solid wood embedment resistances is also one of the important factors for it; however, the above studies [22-25] did not ignore the resistance produced by solid wood. The authors posit that only the resistance produced in plywood should be considered to clarify the influence of the grain direction of plywood. Some studies have conducted embedment tests on plywood specimens [18, 26, 27], and Kamada [28] showed the experimental data of the two grain directions (i.e., the grain direction of surface veneer was parallel or perpendicular to the load direction) using 3-ply plywood made of larch. According to his data, the higher stiffness was observed when the grain direction of surface veneer was parallel to the loading direction, whereas almost same maximum load was observed in the two. In this study, an embedment test was conducted on plywood specimens with grain directions of surface veneers that are parallel and perpendicular to the load direction. Moreover, to understand the resisting mechanism of plywood precisely, the method for calculating the resistance-deformation relationship exhibited by individual parallel and perpendicular veneers was proposed.

\section{Materials and methods Plywood specimen}

Structural plywood made of sugi (Japanese cedar, Cryptomeria japonica D. Don) and karamatsu (Japanese larch, Larix kaempferi Carr.) classified as Class 2 structural plywood in accordance with the Japanese Agricultural Standard [29] was used as the specimen. The plywood was made in Japan and had five plies and a thickness of $12 \mathrm{~mm}$. Eight original sheets were produced by preparing four sheets from each species. Six specimens measuring $50 \mathrm{~mm} \times 100 \mathrm{~mm}$ in size were removed from the original sheets. From one original sheet, three specimens with grain in the surface veneer parallel to the specimen's longitudinal direction (hereafter, longitudinal specimen) and three specimens with grain in the surface veneer parallel to the specimen's transverse longitudinal direction (transverse specimen) were obtained as shown in Fig. 1a. The provided original plywood sheets were composed of veneers with grain parallel and perpendicular to
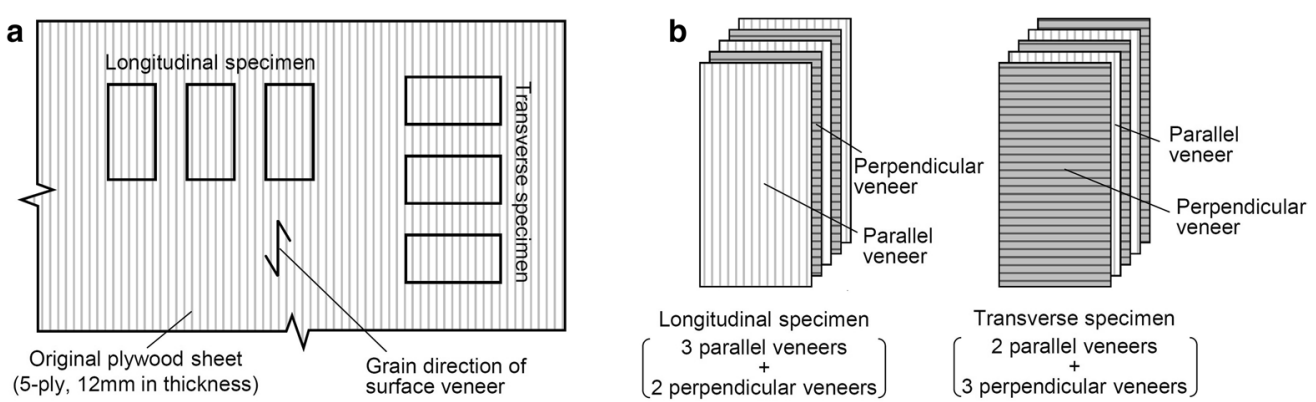

Fig. 1 Plywood specimens. a Sampling method of longitudinal and transverse specimens from an original sheet. b Veneer composition of longitudinal and transverse specimens 
Table 1 Series of plywood specimens

\begin{tabular}{llll}
\hline Series & Species & $\begin{array}{l}\text { Grain direction } \\
\text { of surface } \\
\text { veneer }\end{array}$ & $\begin{array}{l}\text { Number } \\
\text { of specimens }\end{array}$ \\
\hline$S_{0}$ & Sugi (Japanese cedar) & Parallel & 12 \\
$S_{90}$ & & Perpendicular & 12 \\
$K_{0}$ & Karamatsu (Japanese larch) & Parallel & 12 \\
$K_{90}$ & & Perpendicular & 12 \\
\hline
\end{tabular}

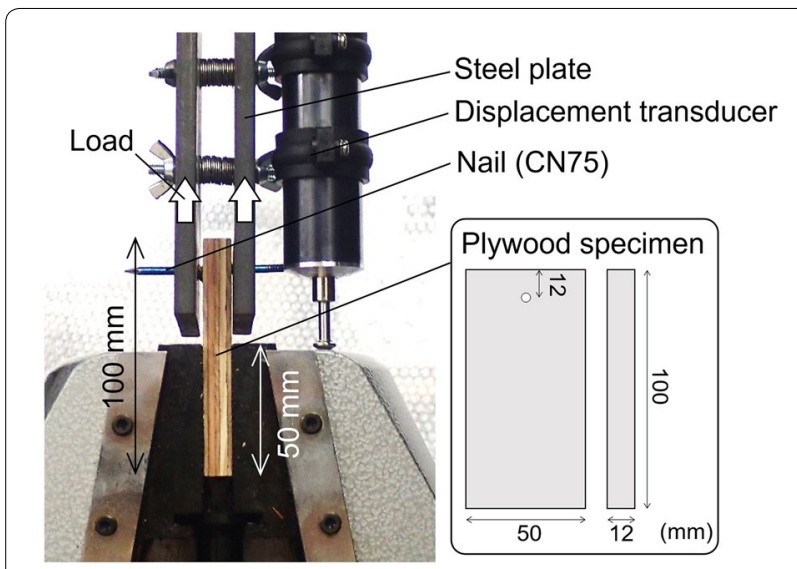

Fig. 2 Plywood specimen and experimental setup

the load direction (hereafter, parallel and perpendicular veneer). The composition of longitudinal and transverse specimens is shown in Fig. 1b. Table 1 presents the four series of specimens. The total number of specimens was 48. These specimens had been placed in a conditioning testing room at $20^{\circ} \mathrm{C}$ and $65 \%$ relative humidity for more than 1 month. The sugi plywood specimen had a density of $423 \pm 22 \mathrm{~kg} / \mathrm{m}^{3}$ (average \pm standard deviation) and moisture content of $10.3 \pm 0.3 \%$; whereas, the karamatsu plywood specimen had a density of $626 \pm 24 \mathrm{~kg} / \mathrm{m}^{3}$ and moisture content of $10.1 \pm 0.3 \%$.

\section{Embedment test}

The embedment test was conducted in accordance with the American Society for Testing Materials (ASTM) standard D1037-12 [30]. However, the specimen size was different from that recommended by the standard method. The experimental setup is shown in Fig. 2. A CN75 nail [31] with a trunk diameter of $3.76 \mathrm{~mm}$ was driven into the specimen at a point $12 \mathrm{~mm}$ below the top side. The specimen was set to an Instron-type tension-compression testing machine (MinebeaMitsumi, Inc., (formerly Shinko Co., Ltd.), TOM-5000X; capacity: $49.5 \mathrm{kN}$ ). The nail part of the specimen was hooked to the holes with diameter of $10 \mathrm{~mm}$ installed to two steel plates, and the gaps between the plates and plywood were maintained at $1 \mathrm{~mm}$. The plywood part was grabbed with a chuck. The embedment load by the nail was applied to the plywood by moving up the steel plates. The load was measured with a load cell (MinebeaMitsumi, Inc., (formerly Shinko Co., Ltd.), TT3-5T; capacity: $49.5 \mathrm{kN}$ ), and deformation was measured with a displacement transducer (Tokyo Sokki Kenkyujo Co., Ltd., CDP-50, capacity $50 \mathrm{~mm}$ ) connected to the steel plate (Fig. 2). The grabbed length in this setup exceeded $50 \mathrm{~mm}$. In this grabbed length, the slip that occurred around the chuck was too small and the slip was ignored in the analysis. Load was applied at the speed of $0.5 \mathrm{~mm} / \mathrm{min}$. After reaching the maximum load, load was continuously applied until it decreased to $80 \%$ of the maximum.

\section{Results and discussion}

\section{Embedment test results}

Figures 3 and 4 present the load-deformation relationships. Each graph shows the results for three longitudinal and three transverse specimens obtained from one original structural plywood. The solid lines represent the longitudinal specimens (Series $S_{0}$ in Fig. 3 and Series $K_{0}$ in Fig. 4), whereas the dotted lines represent the transverse specimens (Series $S_{90}$ in Fig. 3 and Series $K_{90}$ in Fig. 4). The thin lines denote the experimental results, whereas the thick lines denote the average results obtained by averaging the value of the load of the three specimens under the same deformation. Comparing the averaged results of longitudinal and transverse specimens (solid and dotted thick lines) revealed that the longitudinal specimen has a slightly larger load value than the transverse specimen in the rage from the beginning of the testing to approximately $1 \mathrm{~mm}$ in deformation. The difference in the load value decreased as the deformation increased.

Failure mode observed around nail part is illustrated in Fig. 5. An embedment deformation was observed in parallel and perpendicular veneers. At the end of the loading, in parallel veneer, trapezoidal failure occurred; whereas in perpendicular veneer, only the embedment deformation was observed. The failure modes were observed in both longitudinal and transverse specimens.

Stiffness and maximum load were calculated from the load-deformation relationships of all the specimens. Stiffness was derived as the slope with linear regression to the data plots in the range of $10-40 \%$ maximum load through the least-squares method. Figure 6 depicts the average values and the standard deviations of stiffness and maximum load. For example, the average stiffness of Series $S_{0}$ was $3.23 \mathrm{kN} / \mathrm{mm}$, whereas that of Series $S_{90}$ was $1.99 \mathrm{kN} / \mathrm{mm}$, which was considerably lower than that of $S_{0}$. In the case of Series $K_{0}$ and $K_{90}$, average values of 

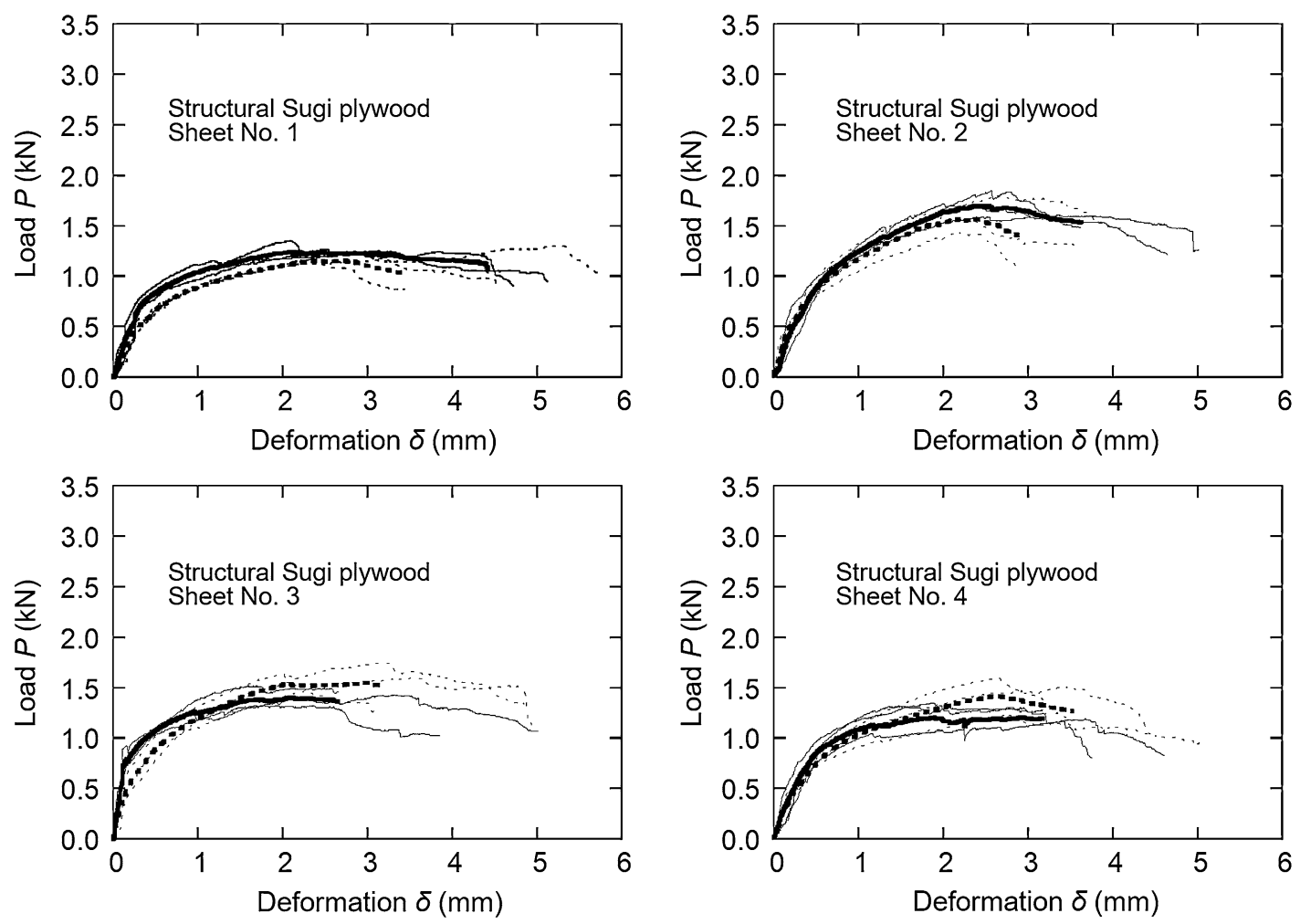

_ Longitudinal specimen $\mathrm{S}_{0}$ (Experimental data) Transverse specimen $\mathrm{S}_{90}$ (Experimental data)

_Longitudinal specimen $\mathrm{S}_{0}$ (Average data)

Transverse specimen $S_{90}$ (Average data)

Fig. 3 Results of embedment test of nail in structural sugi plywood specimens $\left(S_{0}\right.$ and $\left.S_{90}\right)$

stiffness were 3.24 and $2.25 \mathrm{kN} / \mathrm{mm}$, respectively, which also had a large difference between the two. The calculation of the $t$-test showed that there were significant differences in stiffness between $S_{0}-S_{90}$ and $K_{0}-K_{90}$ at a significance level of 0.05 . However, the average maximum load of series $S_{0}$ and $S_{90}$ was 1.45 and $1.49 \mathrm{kN}$, indicating that the two series provide an almost equal value of maximum load. Similar results were observed for the karamatsu plywood: maximum loads of $K_{0}$ and $K_{90}$ were 2.45 and $2.47 \mathrm{kN}$, respectively. The calculation of the $t$-test showed that there were no significant differences in maximum load between $S_{0}-S_{90}$ and $K_{0}-K_{90}$ at a significance level of 0.05 . The results indicated that the grain direction of the surface veneer considerably affects stiffness but negligibly affects maximum load under embedment resistance.

\section{Method for calculating the load-deformation relationships of parallel and perpendicular veneers}

To understand the embedment behavior of plywood precisely, this section describes a method for calculating the resistance produced on individual veneers under embedment loading. This method uses the load-deformation relationships shown in Figs. 3 and 4. Figure 7 shows the model of specimen deformation under nail embedment load. The model was constructed with springs. Figure 7a shows the schematic of the nail region of the specimen. The nail was embedded in the plywood by moving up the steel plates. In the case that the plywood is sufficiently thin, two assumptions could be imposed on the model: First, the nail is bent at the plywood surface. Second, the shape of the nail in the plywood remains linear (i.e., embedment deformation is equal in the five veneers).

On the basis of these assumptions, the specimen was modeled with springs (Fig. 7b). The read value from the displacement transducer (Fig. 2) includes two deformations: the bending deformation of the nail [(A), Fig. 7b] and the embedment deformation of the plywood [(B), Fig. 7b]. The read value from the displacement transducer deformation $\delta$ is the sum of the bending deformation of the nail $\delta_{\text {nail }}$ and the embedment deformation of the plywood $\delta_{\text {ply: }}$ :

$$
\delta=\delta_{\text {nail }}+\delta_{\text {ply }}
$$



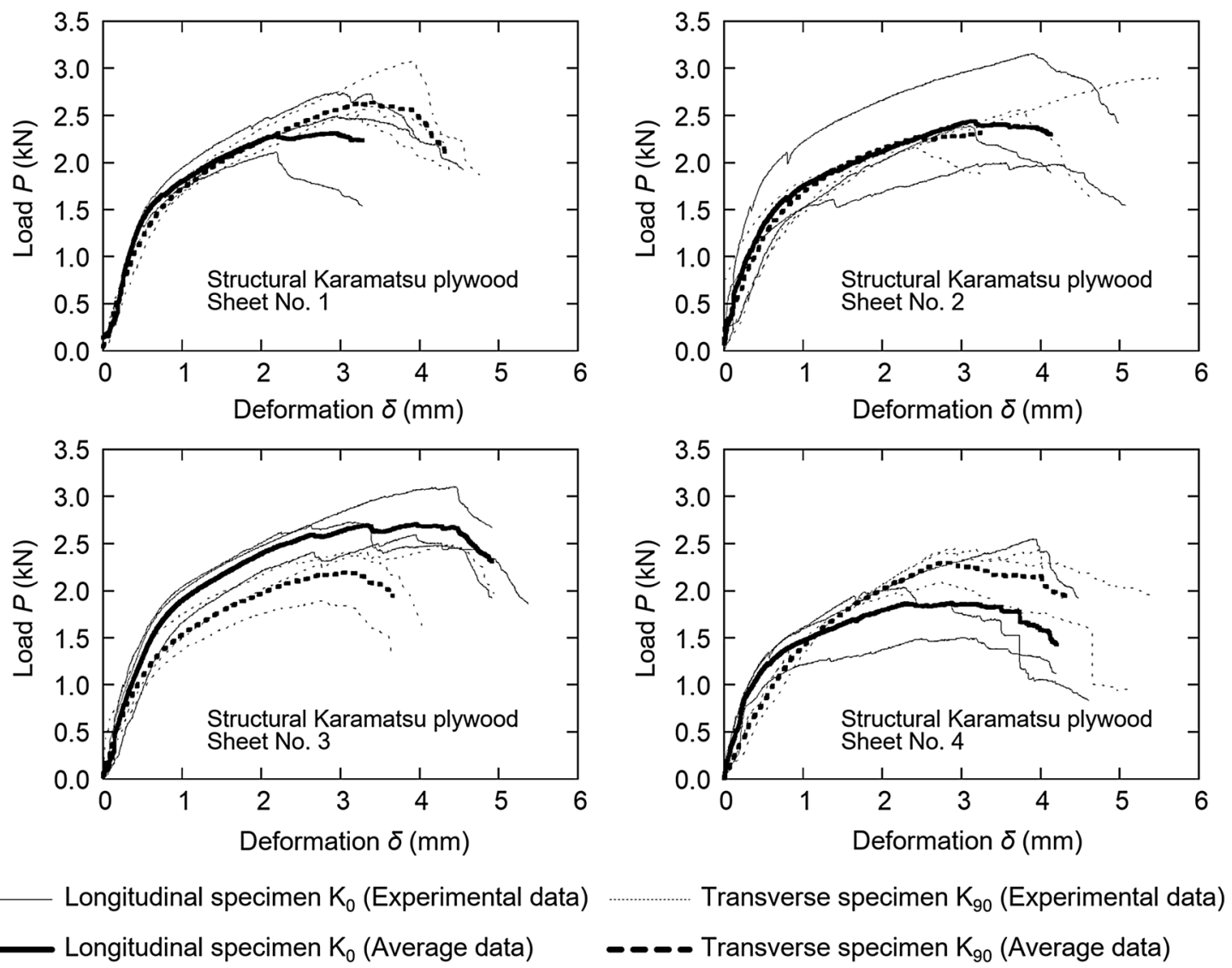

Fig. 4 Results of embedment test of nail in structural karamatsu plywood specimens ( $K_{0}$ and $K_{90}$ )

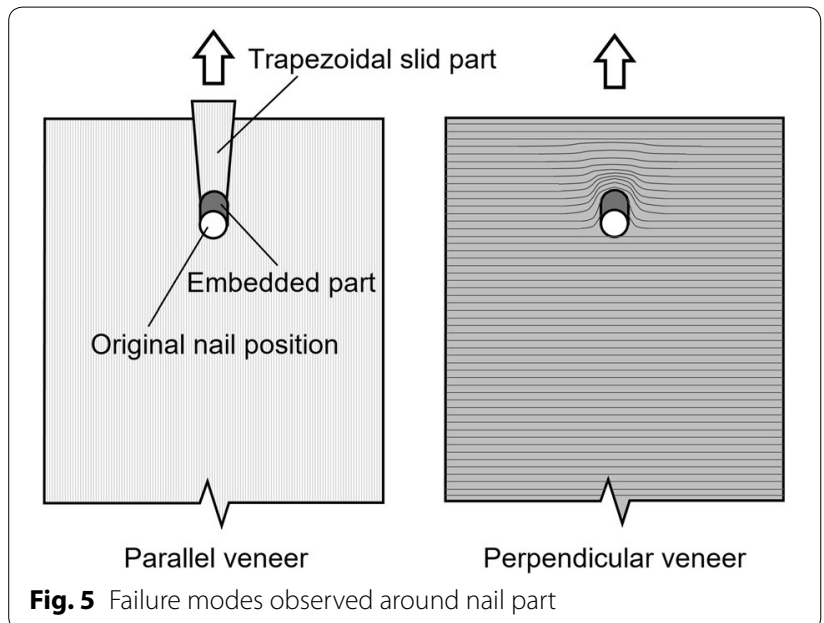

Therefore, the relationship between load $P$ and the embedment deformation of the plywood $\delta_{\text {ply }}$ [i.e., only the relationship in part (B)] could be calculated by obtaining the bending deformation of the nail $\delta_{\text {nail }}$.
The five springs in the model of the embedment deformation of plywood indicate that each veneer was arranged in parallel. Here, the load value of the longitudinal specimen at deformation $\delta_{\text {ply }}$ was denoted as $P_{\text {ply.0. }}$. Similarly, the load value of the transverse specimen at deformation $\delta_{\text {ply }}$ (same deformation with the case

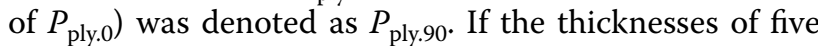
veneers was equal, the two load values could be represented with the nail embedment resistances produced on the parallel $R_{\text {ven. } 0}$ and perpendicular $R_{\text {ven. } 90}$ veneers as follows:

$$
\begin{aligned}
& P_{\text {ply } .0}=3 R_{\text {ven. } 0}+2 R_{\text {ven. } 90} \\
& P_{\text {ply } .90}=2 R_{\text {ven } .0}+3 R_{\text {ven } .90}
\end{aligned}
$$

The resistances $R_{\mathrm{ven} .0}$ and $R_{\mathrm{ven} .90}$ under the embedment deformation of plywood $\delta_{\text {ply }}$ are represented as the simultaneous solution to Eqs. (2) and (3) as follows:

$$
R_{\text {ven. } .}=\frac{3 P_{\text {ply } .0}-2 P_{\text {ply. } .90}}{5}
$$



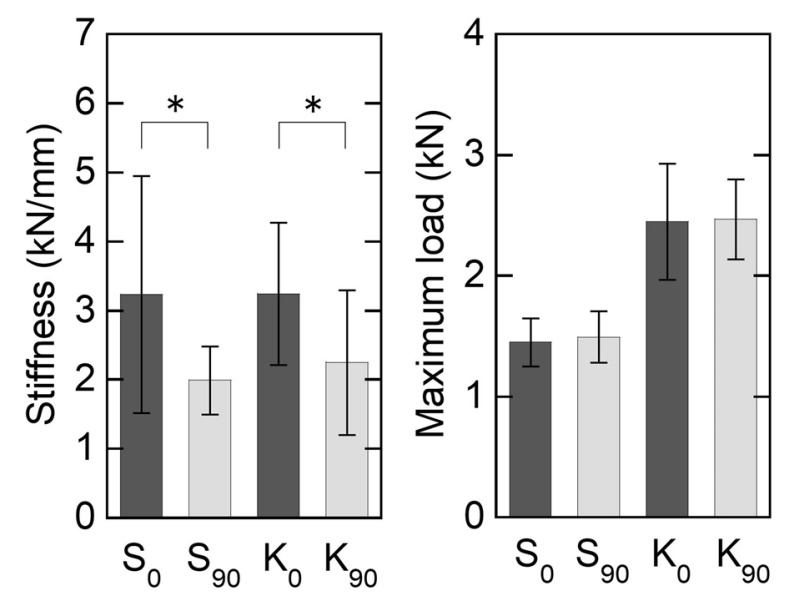

Fig. 6 Average values and the standard deviations of stiffness and maximum load obtained by the embedment test. *Significant difference observed at a significance level of 0.05
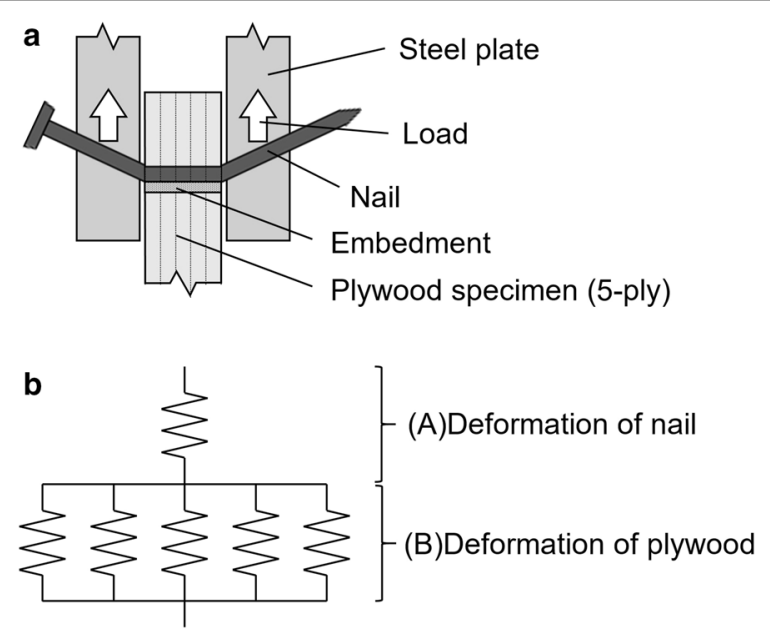

Fig. 7 A model of specimen deformation. a Schematic diagram of deformation. b A spring model

$$
R_{\text {ven.90 }}=\frac{-2 P_{\text {ply } .0}+3 P_{\text {ply } .90}}{5}
$$

The relationships between the resistance and deformation of each veneer could be obtained by calculating the resistances under various $\delta_{\text {ply }}$.

Figure 7 and Eqs. (2)-(5) were supposed that all of thickness of veneers in the provided plywood is equal. However, in the case that a plywood is applied surface smoothing, the assumption is not true because the thickness of surface veneer becomes thin. Although the Eqs. (4) and (5) cannot be used, the resistance produced at individual veneers can be calculated with alternative equations derived by the model similarly to the above.
For this, the thickness of individual should be measured. The resistance can be calculated by following equations with the sum of thickness of parallel veneers $t_{0}$ and sum of thickness of perpendicular veneers $t_{90}$ :

$$
\begin{aligned}
& R_{\text {ven.0 }}^{\prime}=\frac{t_{0} \cdot P_{\text {ply. } 0}-t_{90} \cdot P_{\text {ply. } 90}}{t_{0}^{2}-t_{90}^{2}} \\
& R_{\text {ven.90 }}^{\prime}=\frac{-t_{90} \cdot P_{\text {ply. } 0}+t_{0} \cdot P_{\text {ply } .90}}{t_{0}^{2}-t_{90}^{2}}
\end{aligned}
$$

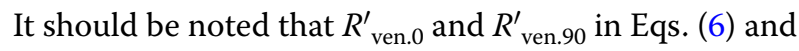
(7) are the resistances per thickness.

\section{Resistance-deformation behavior of each veneer}

The relationship between the load and deformation behavior of each veneer was graphed by the experimental results and the proposed model. The bending deformation of the nail has to be measured through an additional test to enable analysis with the proposed method. The additional test was conducted in the same setup as shown in "Embedment test" of "Materials and methods" section (Fig. 2). The plywood was replaced with a steel plate having a hole (12 $\mathrm{mm}$ in thickness). Therefore, the nail was fixed by the three steel plates, and bent by moving up the two steel plates. During the test, the nail was deformed similarly to the case of using plywood, i.e., it could be assumed that the nail kept lineally at the contacted area between the nail and the replaced steel plate. Figure 8 shows the relationship between load $P$ and deformation $\delta_{\text {nail }}$ obtained through the test. The thin lines represent the experimental data, whereas the thick line represents the averaged data. The deformation of the plywood $\delta_{\text {ply }}$ was calculated using the results of the embedment test (relationship between $P$ and $\delta$ shown in Figs. 3 and 4 ) and the nail test (relationship between $P$ and $\delta_{\text {nail }}$ shown in

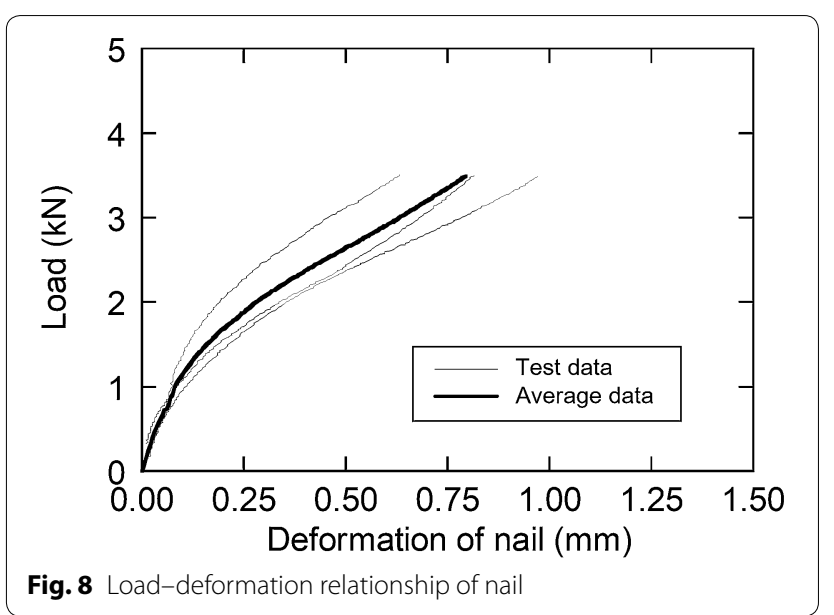


Fig. 8). Under the same load value $P$, the deformation of nail $\delta_{\text {nail }}$ (Fig. 8) was subtracted from the read value from the displacement transducer $\delta$ (Figs. 3 and 4) to calculate the deformation of plywood $\delta_{\text {ply }}$ [Eq. (1)]. The relationship between load $P$ and deformation $\delta_{\text {ply }}$ was obtained by calculating deformation $\delta_{\text {ply }}$ under various load $P$ values.

The relationships between resistances $R_{\mathrm{ven} .0}$ and $R_{\mathrm{ven} .90}$ and the deformation $\delta_{\text {ply }}$ of each veneer were calculated on the basis of the relationships between load $P$ and deformation $\delta_{\text {ply }}$ (Load $P$ was substituted to $P_{\text {ply.0 }}$ and $P_{\text {ply.90 }}$ in the cases of longitudinal and transverse specimens, respectively) using Eqs. (4) and (5). Herein, the relationships were calculated for each original plywood sheet, i.e., the result obtained for one original sheet (shown as solid and dotted thick lines in Figs. 3 and 4) was used for calculation, and the results for other original sheets were calculated through the same method. Four results for the sugi plywood and four results for the karamatsu plywood were obtained and are shown in Fig. 9. The solid lines denote the results for the parallel veneers, whereas the dotted lines denote those for the perpendicular veneers. The thin lines represent the calculated results for one original sheet, whereas the thick lines represent the averaged results obtained with the average value of resistance under the same deformation in four solid/dotted thin lines. Although there is no significant variation in the relationships of plywood specimens (Figs. 3 and 4), the relationships in Fig. 9 have a wide variation. The reason for it is assumed that Fig. 9 focused on the veneers having a characteristic in small thickness, i.e., it was discussed about resistance produced on very local area of wood. The subtle difference in wood properties (e.g., density, ring width, and so on) might influence the relationships of veneers largely. In the following, the relationships of veneers were discussed with average results; however, it is desired that the variation should be taken in consideration when discussing on the relationships in future study.

Comparing the results for parallel and perpendicular veneers (shown as solid and dotted thick lines) reveals that the resistance of the former had a larger slope than the that of the latter during the initial stage of the test. The slope of the parallel veneer began to become small gradually under approximately $0.3 \mathrm{~mm}$ of deformation, then kept the resistance after it. The perpendicular veneer increased its resistance until under approximately $2.0 \mathrm{~mm}$ of deformation. The two thick lines intersected when deformation reached approximately $2.0 \mathrm{~mm}$ (i.e., no difference attributable to the resistance contributed by the grain direction of the veneer was observed under such a large deformation).

Next, the obtained behavior (Fig. 9) was discussed by comparing with past reports on the anisotropic strength properties of plywood. Asano and Tsuzuki [32] attempted to reveal the compression properties of veneer by conducting compression tests on Lauan plywood specimens. They reported that perpendicular veneer shows low modulus of elasticity and strength. This tendency was experimentally confirmed by Kuwamura [33], who subjected veneer specimens to an in-plane compression test under steel-plate loading and found that the compression strength of parallel veneer was approximately 7.5 times higher than that of perpendicular veneer. Although the resisting behavior in this study (Fig. 9) revealed the difference between parallel and perpendicular veneers, the difference was not as large as the results of above reports $[32,33]$. This result may be attributed to differences in loading conditions, loaded with steel plate or nail. Some researchers have reported [34, 35] that when fastener diameter is sufficiently small, the contribution of grain direction to differences in characteristics of embedment
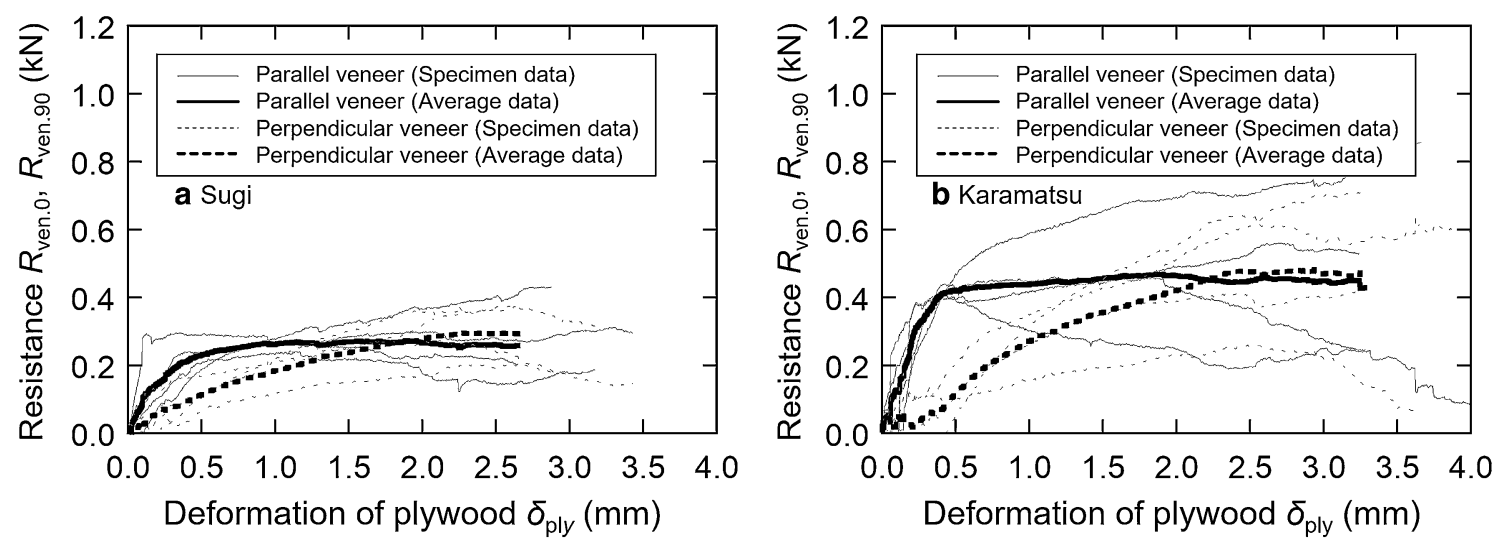

Fig. 9 Resistance-deformation relationship produced on parallel and perpendicular veneers 
behavior decreases. The diameter of the nail used in this study is small enough to reduce the influence of grain direction. This effect, in turn, may have resulted in the smaller differences than compression results obtained under steel-plate loading.

\section{Conclusion}

To analyze the mechanical properties of nailed joint, precisely understanding of the deformation around nail is important. This study conducted the nail embedment test with plywood specimens for comparing the behaviors between different grain direction in surface veneer. Sugi and karamatsu plywood specimens with thicknesses of $12 \mathrm{~mm}$ (5-ply) were loaded by a CN75 nail in accordance with the ASTM setup. This test revealed that the grain direction of the surface veneer considerably affects stiffness but negligibly affects maximum load under embedment resistance.

Additionally, the authors tried to calculate the resisting behavior produced on individual veneers. The presented method clarifies the mechanical contribution of veneers with parallel and perpendicular grain to the resisting behavior of plywood under embedment loading by a nail, which helps to understand the deformation of plywood in detail. The proposed method was developed on the basis of a plywood deformation model constructed with springs arranged in parallel. The experimental results showed that under low deformation, the parallel veneer had a higher slope than the perpendicular veneer. The parallel veneer began to yield under approximately $0.3 \mathrm{~mm}$ of deformation, whereas the perpendicular veneer began to yield under approximately $2.0 \mathrm{~mm}$ of deformation. The deformation behaviors of the two veneers were negligibly different when deformation exceeded $2.0 \mathrm{~mm}$. It is hoped that the results become one of the basic academic knowledge for evaluating the mechanical behavior of nailed joint under loading from many angles.

Future investigations are required to confirm the validity of the proposed method. The proposed method must be applied to plywood specimens with other thicknesses/compositions because this study focused on limited types of plywood specimens. Additionally, the proposed model assumes that the shape of the nail in plywood remains linear and embedment deformation is assumed equal in the five veneers. Under actual loading conditions (e.g., single-shear load), the model should be modified to consider the unequal embedment deformation among veneers in plywood. Therefore, future studies are required to use the presented results for analyzing the mechanical behavior of plywood-sheathed nailed joints.

\section{Authors' contributions}

$\mathrm{KO}$ performed the embedment test, and was a major contributor in writing the manuscript. MH was a co-performer of the test. TS and KM contributed to the interpretation of the data. MH, TS, and KM contributed to improve the quality of the manuscript. All authors read and approved the final manuscript.

\section{Acknowledgements}

This study is funded by Research grant \#201713 of the Forestry and Forest Products Research Institute.

\section{Competing interests}

The authors declare that they have no competing interests.

\section{Availability of data and materials}

The test materials, test method, and the data we recorded are shown in the manuscript with uncolored descriptions.

\section{Funding}

This study was financially supported by Research grant of the Forestry and Forest Products Research Institute (Number: \#201713).

\section{Publisher's Note}

Springer Nature remains neutral with regard to jurisdictional claims in published maps and institutional affiliations.

Received: 2 October 2018 Accepted: 22 January 2019

Published online: 08 February 2019

\section{References}

1. Tsuomi RL, McCutsheon WJ (1978) Racking strength of light-frame nailed walls. J Struct Div 104:1131-1140

2. Kamiya F (1981) Theoretical studies on racking stiffness and strength of wooden sheathed walls. Trans Arch Inst Jap 56(11):86-94 (in Japanese)

3. Easley JT, Foomani M, Dodds RH (1982) Formulas for wood shear walls. J Struct Div 108:2460-2478

4. McCutcheon WJ (1985) Racking deformations in wood shear walls. J Struct Eng 111:257-269

5. Johansen KW (1949) Theory of timber connections. Int Assoc Bridge Struct Eng Pub 9:249-262

6. Smith I, Whale LRJ, Anderson C, Hilson BO, Rodd PD (1988) Design properties of laterally loaded nailed or bolted wood joints. Can J Civ Eng 15:633-643

7. Kuenzi EW (1951) Theoretical design of a nailed or bolted joint under lateral load. Forest Prod Lab, Report No, p 1951

8. Foschi RO (1973) Load-slip characteristics of nails. Wood Sci 7(1):69-76

9. Foschi RO, Bonac T (1977) Load-slip characteristics for connections with common nails. Wood Sci 9(3):118-123

10. Hirai T (1983) Nonlinear load-slip relationship of bolted wood-joints with steel side members II application of the generalized theory of a beam on an elastic foundation. Mokuzai Gakkaishi 29(12):839-844

11. Hirai T (1985) Nonlinear load-slip relationship of bolted wood-joints with steel side members III advanced numerical analysis based on the generalized theory of a beam on an elastic foundation. Mokuzai Gakkaishi 31(3):165-170

12. Mascia NT, Lucia C, Santana O (2009) Remarks on the slip modulus of nailed connections for linear analysis of plywood timber beams. Constr Build Mater 23:2731-2737

13. Eraki MA (1991) Modelling the load-slip behaviour of timber joints with mechanical fasteners. Can J Civ Eng 18:607-616

14. Nishiyama N, Ando N (2003) Analysis of load-slip characteristics of nailed wood joints: application of a two-dimensional geometric nonlinear analysis. J Wood Sci 49:505-512

15. Meghlat EM, Oudjene M, Ait-Aider H, Batoz JL (2013) A new approach to model nailed and screwed timber joints using finite element method. Constr Build Mater 41:263-269

16. Chui YN, Ni C (1997) Load-embedment response of timber to reversed cyclic load. Wood Fiber Sci 29(2):148-160 
17. Jeong GY, Kong JH (2018) Evaluating bearing properties of wood peg connection using four different test methods. Wood Fiber Sci 50(1):20-32

18. Bal BC (2017) Screw and nail holding properties of plywood panels reinforced with glass fiber fabric. CERNE 23(1):11-18

19. Sawata K, Sasaki Y (2018) Lateral strength of nailed timber connections with decay. J Wood Sci 64(5):601-611

20. Jeong GY, Kong JH, Lee SJ, Pang SJ (2018) Comparisons of bearing properties for various oriented glulam using digital image correlation. J Wood Sci 64(3):237-245

21. Bleron L, Duchanois $G$, Thiebaut B (2008) Characteristic properties of embedding strength for the nailing of the gonfolo rose (Qualea rosea Aubl.). Holzforschung 62:86-90

22. Stewart WG (1987) The seismic design of plywood sheathed shear walls. Dissertation, University of Canterbury, Christchurch, New Zealand

23. Harada K, Tsuda Y, Idota H (2016) Shear behavior considering boundary conditions of wood-plywood and angles between grain and load on wood-plywood nailed joint Part 2 Results on nailed joint test (in Japanese). AlJ Tokai Chapter Arch Res Meeting 54:145-148

24. Demirkir C, Colakoglu G (2015) The effect of grain direction on lateral nail strength and thermal conductivity of structural plywood panels. Maderas Cienc Tecnol 17(3):469-478

25. Hagiwara I (1971) An experimental study on strength of nailed joints for plywood. J Faculty Eng, Chiba University 23(43):1-8 (in Japanese)

26. Lederer W, Bader TK, Unger G, Ederhardsteiner J (2016) Influence of different types of reinforcements on the embedment behavior of steel dowels in wood. Eur J Wood Prod 74:793-807
27. Ogawa K, Harada M, Shibusawa T, Miyamoto K (2018) Single shear properties and deformation behavior of nailed joints using various structural panel materials. Mokuzai Gakkaishi 64(4):139-148 (in Japanese)

28. Kamada T (2015) Property of structural panels using on conventional wooden houses. AlJ J Thechnol Des 21:105-108 (in Japanese)

29. Japanese Agricultural Standard (2014) Japanese Agricultural Standard for plywood. (In Japanese). http://www.maff.go.jp/j/jas/jas_kikaku/pdf/ kikaku_53.pdf Accessed 15 May 2018

30. ASTM D1037-12 (2017) Standard test method for evaluating propertie wood-base fiber and particle panel materials. ASTM Internatinal, West Conshohocken, PA

31. JIS A 5508 (2009) JIS standard specification for nails. Japanese Standards Association, Tokyo

32. Asano I, Tsuzuki K (1963) Some anisotropic properties on the strength of the plywood. J Soc Mater Sci Japan 12(121):761-768 (in Japanese)

33. Kuwamura $H$ (2010) Anisotropic elasticity and strength in in-plane behavior of plywood. J Struct Constr Eng, AIJ 75(653):1317-1326 (in Japanese)

34. Architectural Institute of Japan (2011) Nailed joint. "Standard for structural design of timber structures". Maruzen Co., Tokyo, pp 266-278 (in Japanese)

35. Faherty KF (1998) Mechanical fastner and connections. In: Faherty KF, Williamson TG (eds) Wood engineering and construction handbook, 3rd edn. McGraw-Hill, New York, pp 5.3-5.24

\section{Submit your manuscript to a SpringerOpen ${ }^{\odot}$ journal and benefit from:}

- Convenient online submission

- Rigorous peer review

- Open access: articles freely available online

- High visibility within the field

- Retaining the copyright to your article

Submit your next manuscript at springeropen.com 